\title{
Nitrogen Incorporation in $\mathrm{TiO}_{2}$ : Does It Make a Visible Light Photo-Active Material?
}

\author{
B. Viswanathan and K. R. Krishanmurthy \\ National Centre for Catalysis Research, Indian Institute of Technology Madras, Chennai 600 036, India \\ Correspondence should be addressed to B. Viswanathan, bvnathan@iitm.ac.in \\ Received 18 January 2012; Revised 11 April 2012; Accepted 26 April 2012 \\ Academic Editor: Xuxu Wang
}

Copyright (C) 2012 B. Viswanathan and K. R. Krishanmurthy. This is an open access article distributed under the Creative Commons Attribution License, which permits unrestricted use, distribution, and reproduction in any medium, provided the original work is properly cited.

\begin{abstract}
The possibility of hydrogen production by photo-catalytic decomposition of water on titania has provided the incentive for intense research. Titania is the preferred semiconductor for this process, in spite of its large band gap $(\sim 3.2 \mathrm{eV})$ that restricts its utility only in the UV region. Various sensitization methodologies have been adopted to make titania to be active in the visible region. Doping of $\mathrm{TiO}_{2}$ with nitrogen is one such method. The purpose of this presentation is to examine the state and location of nitrogen introduced in $\mathrm{TiO}_{2}$ lattice and how far the shift of optical response to visible radiation can be beneficial for the observed photo-catalysis. The specific aspects that are discussed in this article are: (i) N-doped titania surface adopts a non-native configuration, though the bulk material is still in the native configuration of pure $\mathrm{TiO}_{2}$ (ii) Though the nitrogen doped materials showed optical response in the visible region, the changes/improvements in photo-catalytic activity are only marginal in most of the cases. (iii) The exact chemical nature/state of the introduced nitrogen, and its location in titania lattice, substitutional and/or interstitial, is still unclear (iv) Is there a limit to the incorporation of nitrogen in the lattice of $\mathrm{TiO}_{2}$ ?
\end{abstract}

\section{Introduction}

In titanium-dioxide-promoted photocatalysis or photoelectrochemical applications, the primary objective appears to be "how to make this system respond to visible radiation?" This aspect can be generally termed as sensitization of the semiconductor either intrinsically (conventionally termed as doping even though this may not be the correct connotation when the dopant concentration exceeds a certain limit) or by using visible light absorbing materials (usually dyes or some complex species) [1]. These studies have given rise to many spin offs like understanding of the defect chemistry of the materials, new synthesis strategies for generating these useful semiconducting oxides, and above all the understanding of the physics of the alternate energy levels that are induced by the incorporation of dopants in the original semiconductor. It should be remarked that the efforts to push the photoactive range of these materials to visible region (so that solar spectrum could be effectively utilized) have been the prime motive. It is therefore natural that a variety of synthesis methods for incorporation of nitrogen in $\mathrm{TiO}_{2}$ have been reported in literature $[2,3]$.

\section{Role of Heteroatoms in Titania}

In recent times, there are many reports dealing with heteroatom, (typically, S, C, F, P, B, etc.) substituted (doped or implanted) materials examined as catalysts. The driving force for these studies is the possibility of generating extra allowed energy levels in the wide band gap (e.g., $\mathrm{TiO}_{2}$ ) of the semiconductors. These additional allowed energy levels in the band gap of the semiconductor will not only promote absorption of visible light photons but also bring in alternate pathways for the electron-hole recombination, thus altering their life times which are essential for an effective photocatalyst. Such electronic structure alterations could be induced by these heteroatoms. Though the analysis of such effects may be interesting, this aspect is not considered in this presentation. The scope of this presentation is therefore 
restricted to considering incorporation of nitrogen in $\mathrm{TiO}_{2}$ especially from the points of view of:

(i) what is the exact chemical nature of the substituted and interstitial nitrogen?

(ii) what is the net effect observed in shifting the absorption edge of the semiconductor, and if it does, is there any relationship with the extent of substitution?

(iii) the net changes that have been observed in the photocatalytic activity of substituted systems

(iv) are there any qualitative correlations that can be derived from these observations?

The reason for this self-imposed restriction is that there is considerable literature already available on these systems. In the last five years alone, a simple search with "Nitrogen doped $\mathrm{TiO}_{2}$ " search term in Web of Knowledge returned 940 articles with 93 proceedings and 25 reviews published. Publications, year wise, indicate continued interest in the topic, with 123 in 2007, 146 in 2008, 138 in 2009, 174 in 2010, and 153 in 2011. Proper evaluation of these systems may provide some directions on catalysis promoted by these systems, especially for important reactions like the photo-catalytic decomposition of water or the photocatalytic reduction of carbon dioxide. However, most of the investigations pertain to applications for degradation of organic pollutants in aqueous streams, model compounds therein, and typical dye chemicals.

\section{Status on Nitrogen-Incorporated Titania}

The doped nitrogen assuming substituting anionic positions in (this is already an assumption!) titanium dioxide has attracted attention due to its possible photo-catalytic activity in the visible region [4]. Even though the visible light response of anion doped $\mathrm{TiO}_{2}$ has been reported as early as 1986 by Sato [5], the recent work by Asahi et al. [6] have reopened the interest in this system. In the recent past, few innovative preparation methods have been evolved in literature for $\mathrm{N}, \mathrm{S}, \mathrm{P}, \mathrm{F}$, and $\mathrm{B}$ doped $\mathrm{TiO}_{2}$ catalysts [7-10]. Simultaneously, there are also attempts to rationalize the observed results from theoretical calculations on this system [11-18]. The complexities involved in $\mathrm{N}$-doped titania, especially with respect to the type of $\mathrm{N}$ species, their effects on visible light absorption, and the moderate influence on photocatalytic activity have been covered by Emeline et al. [19]. The current review addresses some of the issues that have emerged from the earlier presentation.

Besides, it is also observed that the state of $N$ in titania and its effectiveness in extending the light absorption edge depend upon the way it is introduced through several preparation methods/techniques. Since this presentation mainly deals with nitrogen introduction in $\mathrm{TiO}_{2}$, it is appropriate to list the typical preparation methods employed in literature, for incorporation of nitrogen in titania and look for possible correlations between nature of $\mathrm{N}$ introduced and preparation methods.

\section{Preparation Methods for Incorporation of Nitrogen in $\mathrm{TiO}_{2}$}

A number of preparative procedures have been adopted for introduction of nitrogen in $\mathrm{TiO}_{2}$ lattice, which are briefly considered below.

(1) Synthesis from solution phase (sol gel method): [20, 21] Titanium isopropoxide $\left(\mathrm{Ti}(\mathrm{OPr})_{4}\right)$ was dissolved in ethanol with dodecylamine and refluxed to get a clear solution. After cooling the solution is neutralized with acetic acid followed by hydrolysis by water. This method has also been followed for multilayer formation of porous $\mathrm{TiO}_{2}$ by dip coating method and then treated with nitrogen source. The preformed $\mathrm{TiO}_{2}$ films were usually annealed in the presence of nitrogen precursors (e.g., $\mathrm{NH}_{3}$ ) [22].

(2) Reaction with ammonia or other N-containing organic substrates like urea, guanidine hydrochloride, or guanidine carbonate: $[23,24]$. A dried commercial $\mathrm{TiO}_{2}$ powder was treated in a flow of dry air or inert gas mixtures containing nearly $50 \%$ ammonia or other nitrogen containing substrates and, the sample is heated to $500-700^{\circ} \mathrm{C}$.

(3) Preparation by plasma treatment [25]: the solid is fixed to a quartz disk and placed in a plasma chamber with heating $\left(400^{\circ} \mathrm{C}\right)$. Purified nitrogen was metered and introduced into the chamber, and the plasma treatment was carried out for a definite time period (of the order of 10 minutes).

(4) Oxidation of $\mathrm{TiN}$ [26-29]: thin film of $\mathrm{TiN}_{x}$ was deposited using DC magnetron sputtering (PVD) and then the film was oxidized. Instead, $\mathrm{TiO}_{2}$ is first sputtered and then annealed in nitrogen. If suitable chemicals are chosen then $\mathrm{TiO}_{2}$ was coated on a substrate and it is then treated with suitable nitrogen source like ammonia.

(5) Electrochemical anodization [30] of titanium foils with suitable nitrogen source has also shown to be a method for controlled incorporation.

(6) Low ion implantation method [31] has also been used to introduce nitrogen in $\mathrm{TiO}_{2}$ single crystals.

It is not clear as to which of the methods give substituted $\mathrm{N}$ and which other methods result in interstitial N. According to one report [32], plasma-enhanced chemical vapor deposition yields substitutional nitrogen, while sol-gel method, annealing in $\mathrm{NH}_{3}$ and chemical methods in general produced predominantly interstitial nitrogen.

None of the methods mentioned above could, however, give clear clues regarding the state of substituted nitrogen. This has to be elucidated by other structural techniques. In most of these studies the amount of nitrogen incorporated is small and hence the X-ray patterns for doped samples resembled that of pure titanium dioxide, and no clear cut changes in the structure could be discerned. 


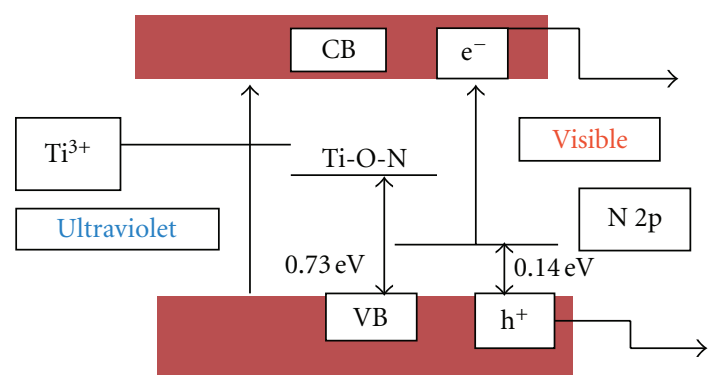

FIgURE 1: Schematic energy level diagram for nitrogen substituted $\mathrm{TiO}_{2}$ [Bare semiconductor absorbs UV radiation while the localized energy levels of nitrogen above valence band facilitate the visible light absorption].

\section{The Chemical Nature of Substituted Nitrogen in $\mathrm{TiO}_{2}$}

The primary motive for nitrogen substitution in $\mathrm{TiO}_{2}$ is to increase the visible light absorption by the semiconductor $[33,34]$. In this sense, the reduction in band gap value with attendant increase in photo-catalytic activity has been reported [4-6, 10,35-38]. This could have arisen due to either mixing of the nitrogen $p$ states with oxygen $2 p$ states on the top of the valence band or by the creation of $\mathrm{N}$ induced mid gap levels as proposed by Asahi et al. [6] (Figure 1). Though these are the generally stated conceptual alterations in the energy states of the doped semiconductor, it is necessary to see the extent of validity of these postulates. However, it must be realized that the possibility of nitrogen substitution in $\mathrm{TiO}_{2}$ provides opportunities for other applications hitherto not examined, namely, oxidation of $\mathrm{CO}$, ethanol, acetaldehyde, and NO removal at room temperature $[6,39,40]$. These newer possibilities may have some far reaching implications.

There seems to be no consensus among the reports on the state of doped nitrogen in $\mathrm{N}-\mathrm{TiO}_{2}$ even though it is considered to be in the anionic form $[4,6,41]$. XPS analyses of $\mathrm{N}-\mathrm{TiO} 2$ show that the $\mathrm{N}$ 1s core level binding energy lies between 396 and $397 \mathrm{eV}$, and it has been claimed that the state of nitrogen to be either nitrogen anion [41] or atomic nitrogen atoms $[6,40]$. Additional $\mathrm{N} 1$ s peaks on $\mathrm{N}-\mathrm{TiO} 2$ observed at binding energies 400 and $402 \mathrm{eV}$ have been attributed to chemisorbed molecular dinitrogen or adsorbed organic compounds [6, 42]. Sakthivel and Kisch [43] observed no anionic-like nitrogen species with binding energy around $396 \mathrm{eV}$ but only observed nitrogen 1s peak at around $404 \mathrm{eV}$ which has been assigned to hyponitrite type nitrogen species. Valentin et al. [35-37] recognized this controversy in the assignment of $\mathrm{N}$ 1s peak position. They observed $\mathrm{N}$ 1s core level at $400 \mathrm{eV}$ and hinted at a lower valence state for N. Recently Chen and Burda [44] observed $\mathrm{N}$ 1s level at $401.3 \mathrm{eV}$ from a detailed XPS investigations of nano- $\mathrm{TiO}_{2}$ and suggested that there is $\mathrm{N}-\mathrm{Ti}-\mathrm{O}$ bond formation due to nitrogen doping and no oxidized nitrogen is present. Sathish et al. [45] have examined this system and attributed the observed N-1s-binding energy at $398.2 \mathrm{eV}$ to be due to N-Ti-O type species present in the system.
The observations of $\mathrm{N}$-1s-binding energy $>400 \mathrm{eV}$ may be attributed to the possible $\mathrm{O}-\mathrm{N}-\mathrm{Ti}$ linkages or some surface oxidation. In a subsequent paper [46] the same authors have tried to substantiate the presence of different types of $\mathrm{N}$ species like Ti-N and $\mathrm{O}-\mathrm{Ti}-\mathrm{N}$ in $\mathrm{N}-\mathrm{TiO}_{2}$ system. It is clear that the XPS results reported on this system require a better understanding.

In order to comprehend the situation, especially the bonding of substituted nitrogen in $\mathrm{TiO}_{2}$, it is necessary that one attempts to summarize the different results reported in literature on XPS studies. This technique probes the core level binding energies of the constituent species, and the value of the binding energy is a reflection of the valence state and charge density around each of the atoms. Since the objective of this presentation is to get clarity on the nature of the nitrogen species, the data on the binding energy of the 1s level of nitrogen in substituted $\mathrm{TiO}_{2}$ are summarized in Table 1.

The data presented in Table 1 give rise to a number of points, which are listed as follows.

It appears that there is some consensus on the state of nitrogen in substituted systems as $\mathrm{Ti}-\mathrm{N}$ with nitrogen substituting for the anion. However, there is no definite information on the valence state of this substituted species. It has been assumed in some cases as $\mathrm{N}^{-}$anion and in some of the other reports the valence state is not exactly mentioned except stating that there is $\mathrm{Ti}-\mathrm{N}$ bonding. This can give rise to the following contemplations.

(a) If $\mathrm{N}^{-}$is the species then the valence state of $\mathrm{Ti}$ has to be different from $\mathrm{Ti}^{4+}$, which has been recognized in some of the reports, but they have not exactly accounted for the valence state of Ti so that electroneutrality is maintained.

(b) It has been tacitly assumed that the N-1s-binding energy is around $\sim 396-397 \mathrm{eV}$, and this peak is mostly present when the nitrogen content in substituted systems is very small. It is generally observed that with increasing nitrogen content the higher binding energy $(\sim 400 \mathrm{eV})$ peak appears which is normally considered to be due to chemisorbed molecular species or interstitial $\mathrm{N}$ or due to the nitrogen of the precursor species employed for $\mathrm{N}$ substitution in $\mathrm{TiO}_{2}$.

(c) The acceptable binding energy value of $\mathrm{N}$ 1s level in substituted systems is around $396-397 \mathrm{eV}$. If this were to be the $1 \mathrm{~s}$ binding energy of the nitrogen species then the species cannot be either in positive or multiple negative valence states. If nitrogen were to assume anionic states (as is generally believed) then nitrogen-1s-binding energy should be around $394 \mathrm{eV}$. This ionic state can also be expected on the basis of electronegativity difference between that of titanium and nitrogen. If it were to be in cationic state, it should be around $400 \mathrm{eV}$ which is less likely on the basis of size and charge. If on the other hand the Ti-N bond were to assume covalent character, the observed nitrogen-1s-binding energy can vary with extent of loading and possibly account for the variations in 
TABle 1: Nitrogen-1s-binding energies in nitrogen substituted $\mathrm{TiO}_{2}$.

\begin{tabular}{|c|c|c|c|}
\hline S. No & $\begin{array}{l}\text { Nitrogen-1s-binding energy in } \\
\mathrm{N}-\mathrm{TiO}_{2} \text { in } \mathrm{eV}\end{array}$ & Assigned to species like & Reference \\
\hline 1 & $\sim 397$ & $\mathrm{~T}-\mathrm{N}$ bonding IBAD & {$[12]$} \\
\hline 2 & 396,400 & Ti-N bond chemisorbed dinitrogen & [13] \\
\hline 3 & $396.2,398.3,400.4$ & Chemically bound, $\mathrm{O}-\mathrm{Ti}-\mathrm{N}$, chemisorbed $\mathrm{N}_{2}$ & [47] \\
\hline 4 & $396.7,398.5$ & $\mathrm{~N}-\mathrm{Ti}$ bonding; symmetric to asymmetric with $\% \mathrm{~N}_{2}$ & {$[15]$} \\
\hline 5 & $398.6,401$ & $\mathrm{~N}$ substituted for oxide, Ti-N-O, incorporated nitrogen & {$[48]$} \\
\hline 6 & $395.4,400.5$ & Ti-O-N unreacted $\mathrm{NH}_{3}$, adsorbed nitrogen & {$[49]$} \\
\hline 7 & 396,400 & $\mathrm{Ti}-\mathrm{N}$, adventitious $\mathrm{N}_{2}$ & {$[14]$} \\
\hline 8 & $396.5,402$ & B-N (bonded to $\mathrm{Ti}$ ) and molecular $\mathrm{N}_{2}$ & {$[50]$} \\
\hline 9 & $397.4-403.7,401.3,396$ & O-Ti-N, chemically bound $\mathrm{N}$ & {$[44]$} \\
\hline 10 & $396,400,402$ & $\mathrm{~N}^{-}$species, chemisorbed $\mathrm{N}_{2}$ & {$[6]$} \\
\hline 11 & 396 & Chemically bound $\mathrm{N}^{-}$ & {$[51]$} \\
\hline 12 & 397 & $\mathrm{Ti}-\mathrm{N}$ concentration dependent & {$[52]$} \\
\hline 13 & 396,400 & $\mathrm{O}-\mathrm{Ti}-\mathrm{N},\left(\mathrm{TiO}_{2-x} \mathrm{~N}_{x}\right)$ & \\
\hline 14 & 398.2 & Covalency of Ti-N bond, anionic N, N-Ti-O & {$[45]$} \\
\hline 15 & 396 & $\beta-\mathrm{N}$ & {$[39]$} \\
\hline 16 & $396.7,399.6$ & Bulk $\mathrm{N}$ in two states nitride species $\mathrm{N}_{2}$-anions $\mathrm{NH}_{x}$ species chemically bound to $\mathrm{H}$ & {$[41]$} \\
\hline 17 & $398.7,400.1$ & C-N bonds, hyponitrite, $\mathrm{O}-\mathrm{Ti}-\mathrm{N}, \mathrm{C}-\mathrm{Ti}-\mathrm{O}, \mathrm{Ti}-\mathrm{O}-\mathrm{N}-\mathrm{C}$ & [53] \\
\hline 18 & $396,399.9$ & $\mathrm{~N}^{-}$substituted, chemisorbed $\mathrm{N}_{2}$ & {$[30]$} \\
\hline 19 & 396.8 & $\beta-\mathrm{N}$, substitution & {$[54]$} \\
\hline 20 & $397,400,403$ & $\mathrm{Ti}-\mathrm{N}$, chemisorbed $\mathrm{N}_{2}$ & {$[55]$} \\
\hline 21 & $396.2,400.2$ & $\beta-\mathrm{N}$ and $\gamma-\mathrm{N}$ & {$[56]$} \\
\hline 22 & 396,400 & Incorporated, trapped $\mathrm{N}_{2}$ & {$[27]$} \\
\hline 23 & $395.6,399.6$ & $\mathrm{~N}^{3-}$ in TiN, Ti-N-O, Ti-O-N & {$[11]$} \\
\hline 24 & 396,400 & $\mathrm{O}-\mathrm{Ti}-\mathrm{N}$ & {$[57]$} \\
\hline 25 & $396,398.8,400.5$ & Substitution, molecular $\mathrm{N}_{2}$ & {$[20]$} \\
\hline 26 & $397-402$ & Substituted nitrogen & {$[23]$} \\
\hline 27 & $397.4,400.3,402.5$ & $\mathrm{Ti}-\mathrm{N}-\mathrm{Ti}, \mathrm{Ti}-\mathrm{O}-\mathrm{N}-\mathrm{O} / \mathrm{Ti}-\mathrm{O}-\mathrm{N}-\mathrm{N}$ & {$[58]$} \\
\hline 28 & $395.8,400$ & $\beta-\mathrm{N}, \mathrm{N}-\mathrm{O}, \mathrm{N}-\mathrm{C}, \mathrm{N}-\mathrm{N}$ & {$[26]$} \\
\hline 29 & 396,400 & $\beta-\mathrm{N}$, molecular $\mathrm{N}_{2}$ & {$[4]$} \\
\hline 30 & $396,400,402$ & $\beta-\mathrm{N}$, others not assigned & {$[29]$} \\
\hline 31 & $396.1,402$ & $\mathrm{~N}-\mathrm{Ti}-\mathrm{O}, \gamma-\mathrm{N}_{2}$ & {$[59]$} \\
\hline 32 & 396,400 & $\beta-\mathrm{N}, \mathrm{N}-\mathrm{O}, \mathrm{N}-\mathrm{C}, \mathrm{N}-\mathrm{N}$ & {$[24]$} \\
\hline 33 & $396,399.5$ & $\beta-\mathrm{N}$, chemisorbed $\mathrm{N}_{2}$, interstitial $\mathrm{O}-\mathrm{N}-\mathrm{Ti}$ & {$[28]$} \\
\hline 34 & $396.2,398.4,400,401.5$ & $\beta-\mathrm{N}$, chemisorbed nitrogen & {$[46]$} \\
\hline 35 & $396,400,402$ & $\beta-\mathrm{N}(396 \mathrm{eV})$ and molecularly chemisorbed $\gamma-\mathrm{N}_{2}(400$ and $402 \mathrm{eV})$ & {$[6]$} \\
\hline 36 & $399.6,396$ & Interstitial nitrogen and substituted nitrogen & {$[60]$} \\
\hline 37 & 400.5 & No substitution nitrogen & {$[61]$} \\
\hline 38 & 399 & Both substitution and interstitial nitrogen & {$[62]$} \\
\hline 39 & 399.6 & $\begin{array}{l}\text { Interstitial nitrogen doping at low levels and nitrogen doping at higher levels; the } \\
\text { limit for this transition is } 1.2 \text { at } \% \text {. }\end{array}$ & [63] \\
\hline 40 & 400 & O-Ti-N bonding & {$[64]$} \\
\hline 41 & $399.2,400.5$ & $\mathrm{C}=\mathrm{N}-\mathrm{C}, \mathrm{N}-\mathrm{C}_{\mathrm{sp} 2},-\mathrm{C}=\mathrm{N}$ & {$[65]$} \\
\hline 42 & 400,402 & Chemisorbed nitrogen & {$[25]$} \\
\hline 43 & 399.5 & Valence state of nitrogen between -2 and -3 & {$[66]$} \\
\hline 44 & $402,399.5$ & Chemisorbed molecular nitrogen, interstitial nitrogen & [67] \\
\hline
\end{tabular}


the binding energy values reported in literature. The literature is unfortunately silent on this aspect for some unknown reasons.

(d) Another important aspect is that the type of species envisaged, namely, either Ti-N or Ti-O-N, could have been present mostly on the surface as they have been detected only in XPS measurements with no indications in the X-ray diffraction patterns, which are nearly the same as the starting $\mathrm{TiO}_{2}$. This means that the surface layers have a non-native configuration as compared to the native configuration that is present in the bulk of the material. If this were to be true, then the reactivity (or even the photocatalytic consequences reported) of the surface should be different from what is generally observed on bare $\mathrm{TiO}_{2}$. Though this has been observed in many publications, they have not been assigned to the changes observed due to the nonnative configurations that may be present on the surfaces of substituted systems [68].

(e) Even though there are reports on the changes in the intensity of the emission due to $\mathrm{N}$ 1s level in the substitution state (namely, around $396-397 \mathrm{eV}$ ), it is not clear from the available literature to what percentage the nitrogen substitution in anionic position will take place and when the signal due to molecularly chemisorbed nitrogen species starts to appear. The changes observed or expected in the optical spectrum are critically dependent on this parameter.

(f) Observation of two XPS peaks at $396-398 \mathrm{eV}$ and $400-402 \mathrm{eV}$ possibly indicates the presence of substitutional as well as interstitial nitrogen, respectively, in titania lattice though the exact chemical nature is not clear.

(g) Nitrogen incorporation in titanium dioxide has thus been claimed through a number of preparation methods $[65,69]$. It is generally presumed that the visible light photo activity of the resultant material is due to incorporation of nitrogen in the lattice. An alternate postulate is that nitrogen precursors could give rise to light active molecular species on the surface (dye like) which function as sensitizers for the observed visible light photo-activity [70-73]. However, this concept cannot account wherein molecular nitrogen or other molecules, which on decomposition yield molecular nitrogen, are employed for the preparation of nitrogen substituted $\mathrm{TiO}_{2}$.

The data presented in Table 1 show that the nitrogen incorporated in $\mathrm{TiO}_{2}$ is mostly in the substitution position for the anion conventionally designated as $\beta-\mathrm{N}$ species. Several investigations have reported peaks at $400-402 \mathrm{eV}$ indicating presence of interstitial nitrogen as well. However, there is no clear cut statement on the valence state of the nitrogen. Is it a trivalent anion? Or at least an anion with negative charge on substituted nitrogen? The $\mathrm{N}$ substituted systems on further incorporation of nitrogen gives rise to molecularly chemisorbed species. This observation leads one to make an estimate of the possible extent of substitution in

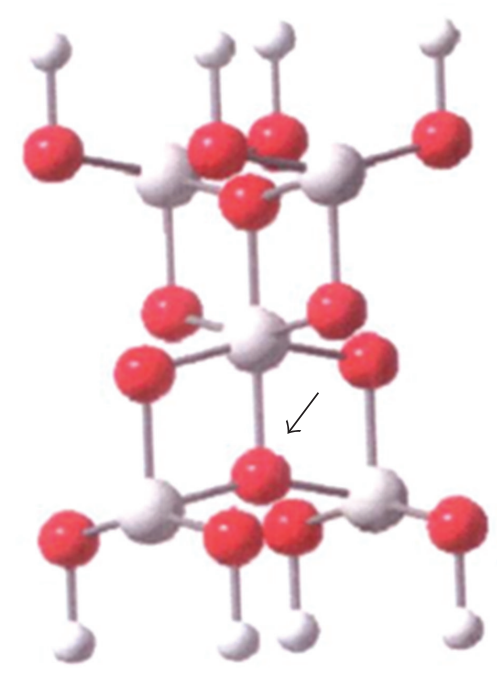

Figure 2: Model of the cluster $\left(\mathrm{Ti}_{5} \mathrm{O}_{14} \mathrm{H}_{8}\right)$ [the position of the replaced oxygen is shown by an arrow].

$\mathrm{TiO}_{2}$. In any of the studies reported, this aspect has not been clearly stated. This could be deduced by the shift of the band gap value as a function of the extent of nitrogen substitution. A rough estimate of the data available in literature shows that the substituted nitrogen cannot exceed $10 \%$. However, it is necessary to examine the band structure alterations that can take place by the substitution of anions in titanium dioxide by nitrogen anion.

\section{N Substitution Theoretical Approaches}

A few theoretical studies have been reported on this aspect on the basis of the calculation of the density of states (DOS). The salient points that emerge out of these theoretical studies are $[12-15,17,18]$

(1) the nitrogen $2 p$ states give rise to allowed energy states just above the valence band of the semiconductor (Figure 1).

(2) the $3 \mathrm{~d}$ states of the metal provide allowed energy levels near the conduction band.

(3) the transition from the allowed $2 p$ states of nitrogen to the conduction band accounts for the visible light activity of these doped systems.

(4) Asahi et al. [6] believe that the Nitrogen 2p and oxygen $2 \mathrm{p}$ states hybridize and thus account for the band gap narrowing. This statement has been substantiated by the calculations of Sakai et al. [13] and that of Li et al. [12] Shang et al. [14], and Sathish et al. [18]. The model calculations have been made on a typical cluster $\left[\mathrm{Ti}_{5} \mathrm{O}_{14} \mathrm{H}_{8}\right]$ (Figure 2).

The position of the substituted nitrogen in the place of oxygen atom is shown by arrow. This corresponds to an anionic position in the $\mathrm{TiO}_{2}$ lattice. The density of states (DOS) calculation has shown the reduction in the band 
TABLE 2: $2 \mathrm{p}_{3 / 2}$ binding energy values for Ti in $\mathrm{N}$-substituted $\mathrm{TiO}_{2}$.

\begin{tabular}{|c|c|c|c|}
\hline S. No & $\begin{array}{l}\text { Binding energy of } 2 \mathrm{p}_{3 / 2} \text { level of } \\
\text { Ti In } \mathrm{N}-\mathrm{TiO}_{2}(\text { in } \mathrm{eV})\end{array}$ & Assigned as & Reference \\
\hline 1 & 458 & Ti in $4+$ oxidation state & {$[27]$} \\
\hline 2 & $459.3,458.5$ & Electronic interaction is different, covalency & {$[45]$} \\
\hline 3 & $<459.1$ & Substitution of $\mathrm{N}$ Multiple oxidation states $+3+2$ & {$[52]$} \\
\hline 4 & +0.9 and +2.1 with respect $\mathrm{TiO}_{2}$ & Intrinsic defects implanted nitrogen & {$[31]$} \\
\hline 5 & 458 & Same as in $\mathrm{TiO}_{2}$ & [27] \\
\hline 6 & $458.6,456.2$ & Ti in +3 and +4 states & [59] \\
\hline 7 & 458.2 & Shifted to lower value, electron density increases, covalency & {$[26,53]$} \\
\hline 8 & $459.2,456.1$ & $\begin{array}{l}\text { Decrease by } 05-02 \mathrm{eV} \text { with respect to } \mathrm{TiO}_{2}, \mathrm{~N}-\mathrm{Ti}-\mathrm{N} \text { or } \mathrm{O}-\mathrm{Ti}-\mathrm{N}, \mathrm{N}-\mathrm{Ti}-\mathrm{N} \text {, } \\
\text { O-Ti-N }\end{array}$ & {$[58]$} \\
\hline 9 & $458.1,463.8$ & $\mathrm{Ti}-\mathrm{N}$ bonds shifts to lower values & {$[23]$} \\
\hline 10 & 457.5 & $\mathrm{Ti}-\mathrm{N}$ & [20] \\
\hline
\end{tabular}

gap which is attributed to the orbital mixing of the hetero atom with oxygen $2 \mathrm{p}$ and $\mathrm{Ti} 3 \mathrm{~d}$ states as stated earlier. It is presumed that the energetic considerations show that the nitrogen $2 p$ states can mix with both the $2 p$ state of oxide ions and also the $3 \mathrm{~d}$ state of the titanium ions thus accounting for the reduction in the band gap with the possibility of visible light active nature of $\mathrm{N}$-doped $\mathrm{TiO}_{2}$. It has been shown that both the top of the valence band and the bottom of the conduction band are broadened due to nitrogen doping in $\mathrm{TiO}_{2}$.

The points of relevance are

(i) does nitrogen doping in $\mathrm{TiO}_{2}$ directly reduces the value of the band gap of $\mathrm{TiO}_{2}$ ?

(ii) does the substitution of nitrogen give rise to allowed energy states in the band gap of the semiconductor thus accounting for the visible light response of the doped semiconductor?

(iii) how does the substitutional/interstitial nitrogen influence the activity?

These issues have not yet been resolved.

\section{The Nature of Titanium Species in N-Substituted $\mathrm{TiO}_{2}$}

Having seen that the exact chemical nature of nitrogen in $\mathrm{N}$-substituted $\mathrm{TiO}_{2}$ is subject to controversy, it is natural to expect some changes in the $2 \mathrm{p}_{3 / 2}$ binding energy of Ti. This is required since nitrogen can either take up the position of the oxide ions or can also replace the cations. In addition, since the difference in the values of the electronegativity of nitrogen and titanium is 1.5 as against the value of 1.9 for $\mathrm{Ti}$ and oxygen, one can expect even if nitrogen were to take up the anionic position, the bonding may involve in some covalent character and hence the $2 \mathrm{p}_{3 / 2}$-binding energy of titanium can be different from what is observed for $\mathrm{Ti}^{4+}$.

The reported XPS results on the binding energy of $\mathrm{Ti}$ $2 \mathrm{p}_{3 / 2}$ in nitrogen-substituted $\mathrm{TiO}_{2}$ are given in Table 2 .

Though most of the studies on the N-substituted $\mathrm{TiO}_{2}$ systems have clearly dealt with the XPS of N 1s level, they are not making any significant comment of the corresponding features of the Ti $2 \mathrm{p}$ XP spectra. This study could have given some information on the state of nitrogen in the substituted systems. If nitrogen incorporation were to take place similar to TiN-like species then $\mathrm{Ti}$ could have been present in +3 oxidation state and the covalency of the bond could have increased, and it could have resulted in the decrease in the binding energy of $2 \mathrm{p}_{3 / 2}$ level of Ti present in $\mathrm{N}-\mathrm{TiO} 2$. However, most of the studies have not reported explicitly this observation and also in some of the studies, they have not observed the shift to lower binding energy values with respect to what is observed in $\mathrm{TiO}_{2}$, which possibly implies that nitrogen is not either substituted for oxygen or the species generated are not like TiN.

\section{Nitrogen in Interstitial Sites in Titania}

According to Asahi et al. [6] only substitutional type of $\mathrm{N}$ doping is possible. This leads to mixing of the $2 \mathrm{p}$ states of oxygen from titania with the $2 \mathrm{p}$ states of $\mathrm{N}$ and results in intra band states which in turn can effectively narrow down the band gap, thereby facilitating visible light. Interstitial type $\mathrm{N}$ doping was found to be ineffective.

In contrast, Valentin et al. [35-37] propose that incorporation of nitrogen in substitutional state is more effective in the formation of localized levels within the band gap and conclude that both substitutional and interstitial nitrogen may exist with energy levels as shown in (Figure 1) and depending on the preparation (oxygen partial pressure) conditions. According to Valentin et al. [35-37], substitutional nitrogen states lie just above valence band, by $0.14 \mathrm{eV}$, and interstitial nitrogen states lie higher in the gap at $0.73 \mathrm{eV}$. Two N1s XPS peaks, one observed at $396 \mathrm{eV}$ (substitutional) and the other at $400 \mathrm{eV}$ (interstitial) nitrogen species lend credence to this theory. It is also known that nitrogen can substitute the $\mathrm{Ti}$ site in $\mathrm{TiO}_{2}$.

Hence, at present, it is not clear in what state nitrogen is introduced in $\mathrm{TiO}_{2}$. No correlations exist between the method adopted for $\mathrm{N}$ incorporation and the type of $\mathrm{N}$ in the lattice, substitutional, or interstitial. In the absence of clear understanding of the state of nitrogen introduced in 
TABLe 3: Typical photocatalytic studies reported on N-substituted $\mathrm{TiO}_{2}$.

\begin{tabular}{lcc}
\hline S. No & Photo-catalytic studies on $\mathrm{N}-\mathrm{TiO}_{2}$ & Reference \\
\hline 1 & $\begin{array}{c}\text { Photo-activity using stearic acid, no } \\
\text { visible-light-induced activity }\end{array}$ & {$[27]$} \\
& Photo degradation of Phenol N-TiO & , anatase \\
2 & is higher & {$[55]$} \\
& Degradation of methylene blue, no specific & {$[30,39,45$,} \\
3 & trend with respect to nitrogen substitution & $46]$ \\
4 & Photo-degradation of methyl orange & {$[48,53$,} \\
5 & Photodecomposition of isopropyl alcohol & {$[58]$} \\
6 & Photo-electrochemical decomposition of water & {$[52]$} \\
7 & Degradation of ethylene glycol & {$[76]$} \\
8 & Decomposition of 2-chlorophenol & {$[14,23]$} \\
9 & Decomposition of VOC and Rhodamine B & {$[29]$} \\
10 & Decomposition of acetaldehyde & {$[6]$} \\
\hline
\end{tabular}

titanium dioxide, it is difficult to interpret the photo-catalytic activity observed with these systems since the creation of new adsorption centers could also be one of the reasons for the observed photo-catalytic effect even though the photon absorption range could have shifted to visible range.

\section{Photo-Catalytic Studies on Nitrogen-Introduced $\mathrm{TiO}_{2}$}

It is known that the primary reason for substitution of nitrogen in $\mathrm{TIO}_{2}$ is to extend the photon absorption range to visible region. Even though, this expectation is mostly fulfilled, as substantiated from the optical response of a typical system reproduced in Figure 3, its effects on photocatalytic activity are yet to be realized in expected terms.

Cho et al. [74] have studied the photo-catalytic activity of nitrogen-doped $\mathrm{TiO}_{2}$ hollow nanospheres and concluded that the activity under visible light was superior to that of pure $\mathrm{TiO}_{2}$ or Degussa P-25.

A compilation of the photocatalytic activity studies on $\mathrm{N}$-doped titania is presented in Table 3.

It is surprising to note that the photo-catalytic activity of $\mathrm{N}-\mathrm{TiO} 2$ has been restricted to the same type of reactions (namely decomposition of organic substrates), and considerable increase in the reactivity is not observed for visible light irradiation. This casts doubt on the attempts that are made for shifting the absorption to visible range by sensitizing the semiconductor with the hope that more of the solar radiation can be utilized. This postulate is not established till now. It appears that one has to reexamine the methodology for the selection of materials for photo/photo-electrochemical decomposition of water where one is searching for a semiconductor which can be photo active in the visible range.

Photo-catalytic decomposition of volatile organic compounds and decontamination of water, though, may be relevant from environmental control point of view the

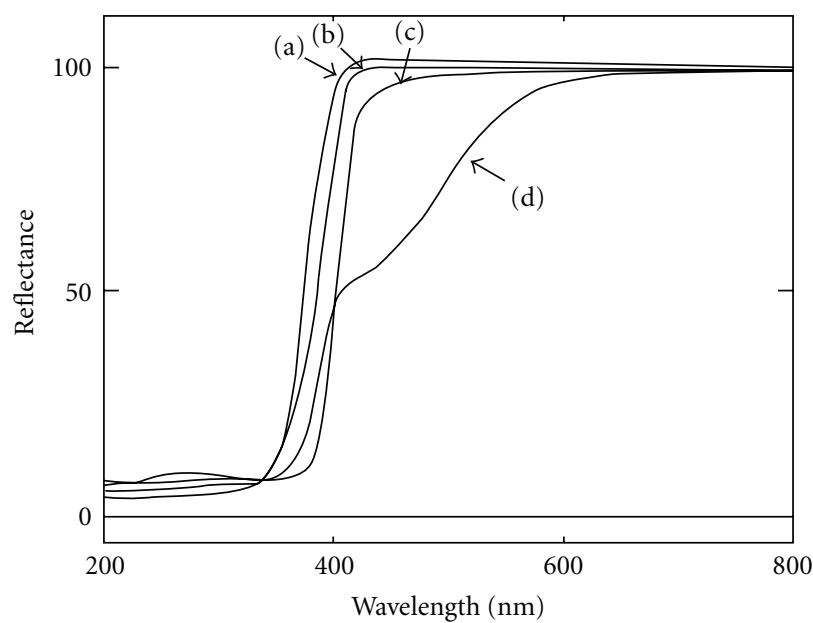

Figure 3: UV-vis reflectance spectra of (a) $\mathrm{TiO}_{2}$, (b) P-25, (c) undoped hollow $\mathrm{TiO}_{2}$ sphere, and (d) $\mathrm{N}$-doped hollow $\mathrm{TiO}_{2}$ sphere [74].

photo-catalytic decomposition of water for the production of fuel (namely, hydrogen) may be of greater relevance and importance. The studies so far reported in literature on nitrogen-doped $\mathrm{TiO}_{2}$ have not shown considerable enhancement of the decomposition of water by increasing absorption in the visible range. Besides Kitano et al. [77] observed that $\mathrm{N}$-doped titania film after photo electrolysis of water under visible irradiation showed a decrease in $\mathrm{N}$ concentration at surface layer indicating that the surface was oxidized during electrolysis. Such stability issues $[77,78]$ with Ndoped titania usage need to be addressed and improved.

\section{Conclusions}

(1) It is not clear from the results reported in literature that nitrogen introduction in $\mathrm{TiO}_{2}$ lattice can promote the phase transformation from anatase to rutile. It is known that anatase to rutile phase transformation is either inhibited or promoted by the addition of substances like $\mathrm{K}_{2} \mathrm{O}, \mathrm{P}_{2} \mathrm{O}_{5}, \mathrm{Li}_{2} \mathrm{O}$ and carbon in the former three cases the transformation was inhibited while in the case of carbon it is accelerated [79-81]. However, the available reported literature is not clear if introduction of nitrogen in $\mathrm{TiO}_{2}$ lattice can alter or promote the phase transformation from anatase to rutile. This can be considered as an indirect evidence for nitrogen not incorporated in the lattice.

(2) Interrelationships between the methods adopted for $\mathrm{N}$ introduction and chemical nature and location of $\mathrm{N}$ in $\mathrm{TiO}_{2}$ lattice are yet to be understood.

(3) Maximum/optimum doping of $\mathrm{N}$ that could be achieved, and its effect on photoactivity is another aspect that needs further study.

(4) If the X-ray diffraction patterns for $\mathrm{N}$-doped $\mathrm{TiO}_{2}$ remain the same as that of pure $\mathrm{TiO}_{2}$, then the effect of $\mathrm{N}$ introduction should have been minimal and hence the surface configuration could be different 
from that of the bulk native structure. If this architecture is possible, then optical absorption changes observed could have arisen out of the surface layers and hence only the adsorptive properties could have altered, accounting for the increased photo-catalytic oxidation of organic substrates.

(5) Stability of the N-doped titanium dioxide under irradiation during photo-electrolysis of water [78] is a challenge to be addressed.

\section{Acknowledgments}

Grateful thanks are due to Department of Science and Technology, Government of India for the generous support of the National Centre for Catalysis Research, at IIT Madras. The authors also wish to thank one of the reviewers for his remarks for the improvement of the paper.

\section{References}

[1] B. Viswanathan, Photo/Electrochemistry \& Photobiology in the Environment, Energy and Fuel, Research Signpost, 2005.

[2] M. Kitano, M. Maatasuoka, M. Ueshima, and M. Anpo, "Recent developments in titanium oxide-based photocatalysts," Applied Catalysis A, vol. 325, no. 1, pp. 1-14, 2007.

[3] K. Hashimoto, H. Irie, and A. Fujishima, " $\mathrm{TiO}_{2}$ photocatalysis: a historical overview and future prospects," Japanese Journal of Applied Physics, vol. 44, no. 12, pp. 8269-8285, 2005.

[4] H. Irie, S. Washizuka, N. Yoshino, and K. Hashimoto, "Visiblelight induced hydrophilicity on nitrogen-substituted titanium dioxide films," Chemical Communications, vol. 9, no. 11, pp. 1298-1299, 2003.

[5] S. Sato, "Photo catalytic activity of $\mathrm{NO}_{x}$ doped $\mathrm{TiO}_{2}$ in the visible region," Chemical Physics Letters, vol. 123, no. 1-2, pp. 126-128, 1986.

[6] R. Asahi, T. Morikawa, T. Ohwaki, K. Aoki, and Y. Taga, "Visible-light photocatalysis in nitrogen-doped titanium oxides," Science, vol. 293, no. 5528, pp. 269-271, 2001.

[7] T. Morikawa, R. Asahi, T. Ohwaki, K. Aoki, and Y. Taga, "Band-gap narrowing of titanium dioxide by nitrogen doping," Japanese Journal of Applied Physics 2, vol. 40, no. 6A, pp. L561-L563, 2001.

[8] T. Umebayashi, T. Yamaki, H. Hoh, and K. Asai, "Band gap narrowing of titanium dioxide by sulfur doping," Applied Physics Letters, vol. 81, no. 3, pp. 454-456, 2002.

[9] S. C. Moon, H. Mametsuka, S. Tabata, and E. Suzuki, "Photocatalytic production of hydrogen from water using $\mathrm{TiO}_{2}$ and $\mathrm{B} / \mathrm{TiO}_{2}$," Catalysis Today, vol. 58, no. 2, pp. 125-132, 2000.

[10] R. Beranek, B. Neumann, S. Sakthivel et al., "Exploring the electronic structure of nitrogen-modified $\mathrm{TiO}_{2}$ photo catalysts through photo current and surface photo voltage studies," Chemical Physics, vol. 339, no. 1-3, pp. 11-19, 2007.

[11] J. Wang, D. N. Tafen, J. P. Lewis et al., "Origin of photocatalytic activity of Nitrogen-doped $\mathrm{TiO}_{2}$ nanobelts," Journal of the American Chemical Society, vol. 131, no. 34, pp. 12290-12297, 2009.

[12] Q. Li, J. Xue, W. Liang, J. H. Huang, and J. K. Shang, "Enhanced visible-light absorption in heavily nitrogen-doped $\mathrm{TiO}_{2}$," Philosophical Magazine Letters, vol. 88, no. 3, pp. 231238, 2008.
[13] Y. W. Sakai, K. Obata, K. Hashimoto, and H. Irie, "Enhancement of visible light-induced hydrophilicity on nitrogen and sulfur-codoped $\mathrm{TiO}_{2}$ thin films," Vacuum, vol. 83, no. 3, pp. 683-687, 2008.

[14] G. Shang, H. Fu, S. Yang, and T. Xu, "Mechanistic study of visible-light-induced photodegradation of 4-chlorophenol by $\mathrm{TiO}_{2-x} \mathrm{~N}_{x}(0.021<x<0.049)$ with low nitrogen concentration," International Journal of Photoenergy, vol. 2012, Article ID 759306, 9 pages, 2012.

[15] J. W. Chai, M. Yang, Q. Chen et al., "Effects of nitrogen incorporation on the electronic structure of rutile- $\mathrm{TiO}_{2}$," Journal of Applied Physics, vol. 109, no. 2, Article ID 023707, 2011.

[16] A. N. Enyashin, V. V. Ivanovskaya, Y. N. Makurin, V. G. Bamburov, and A. L. Ivanovskii, "Electronic structure of doped titanium dioxide nanotubes," Doklady Physical Chemistry, vol. 391, no. 4-6, pp. 187-190, 2003.

[17] M. R. Benam, "First principles studies of the effect of nitrogen impurities on the energy gap of rutile $\mathrm{TiO}_{2-x} \mathrm{~N}_{x}$ by pseudo potential approaches," Journal of Engineerign and Applied Sciences, vol. 6, p. 18, 2011.

[18] M. Sathish, M. Sankaran, B. Viswanathan, and R. P. Viswanath, "DFT studies on anionic hetero atom (N or/and S) substitution in $\mathrm{TiO}_{2}$," Indian Journal of Chemistry A, vol. 46, no. 6, pp. 895-898, 2007.

[19] A. V. Emeline, V. N. Kuznetsov, V. K. Rybchuk, and N. Serpone, "Visible-light-active titania photocatalysts: the case of $\mathrm{N}$ doped $\mathrm{TiO}_{2}$-properties and some fundamental issues," International Journal of Photoenergy, vol. 2008, Article ID 258394, 19 pages, 2008.

[20] C. Kusumawardani, K. Indiana, and Narsito, "Synthesis of nanocrystalline $\mathrm{N}$-doped $\mathrm{TiO}_{2}$ and its application on high efficiency of dye-sensitized solar cells," Science Journal UBU, vol. 1, no. 1, pp. 1-8, 2010.

[21] S. Livraghi, M. C. Paganini, E. Giamello, A. Selloni, C. Di Valentin, and G. Pacchioni, "Origin of photoactivity of nitrogen-doped titanium dioxide under visible light," Journal of the American Chemical Society, vol. 128, no. 49, pp. 15666$15671,2006$.

[22] M. Gartner, P. Osiceanu, M. Anastasescu et al., "Investigation on the nitrogen doping of multilayered, porous $\mathrm{TiO}_{2}$ thin films," Thin Solid Films, vol. 516, no. 22, pp. 8184-8189, 2008.

[23] S. Buzby, M. A. Barakat, H. Lin et al., "Visible light photocatalysis with nitrogen-doped titanium dioxide nanoparticles prepared by plasma assisted chemical vapor deposition," Journal of Vacuum Science and Technology B, vol. 24, no. 3, pp. 1210-1214, 2006.

[24] Y. Nosaka, M. Matsushita, J. Nishino, and A. Y. Nosaka, "Nitrogen-doped titanium dioxide photocatalysts for visible response prepared by using organic compounds," Science and Technology of Advanced Materials, vol. 6, no. 2, pp. 143-148, 2005.

[25] C. Chen, H. Bai, S. M. Chang, C. Chang, and W. Den, "Preparation of $\mathrm{N}$-doped $\mathrm{TiO}_{2}$ photocatalyst by atmospheric pressure plasma process for VOCs decomposition under UV and visible light sources," Journal of Nanoparticle Research, vol. 9, no. 3, pp. 365-375, 2007.

[26] L. Zhu, J. Xie, X. Cui, J. Shen, X. Yang, and Z. Zhang, "Photoelectrochemical and optical properties of $\mathrm{N}$-doped $\mathrm{TiO}_{2}$ thin films prepared by oxidation of sputtered TiNx films," Vacuum, vol. 84, no. 6, pp. 797-802, 2010.

[27] J. M. Yates, M. G. Nolan, D. W. Sheel, and M. E. Pemble, "The role of nitrogen doping on the development of visible lightinduced photocatalytic activity in thin $\mathrm{TiO}_{2}$ films grown on 
glass by chemical vapour deposition," Journal of Photochemistry and Photobiology A, vol. 179, no. 1-2, pp. 213-223, 2006.

[28] C. J. Tavares, S. M. Marques, T. Viseu et al., "Enhancement of the photocatalytic nature of nitrogen-doped PVD-grown titanium dioxide thin films," Journal of Applied Physics, vol. 106, Article ID 113535, 2009.

[29] T. Morikawa, R. Asahi, T. Ohwaki, K. Aoki, K. Suzuki, and Y. Taga, ReD Review of Toyota CRDI, vol. 40, p. 46, 2005.

[30] D. Chen, Z. Jiang, J. Geng, Q. Wang, and D. Yang, "Carbon and nitrogen co-doped $\mathrm{TiO}_{2}$ with enhanced visible-light photocatalytic activity," Industrial \& Engineering Chemistry Research, vol. 46, no. 9, pp. 2741-2746, 2007.

[31] M. Batzill, E. H. Morales, and U. Diebold, "Surface studies of nitrogen implanted $\mathrm{TiO}_{2}$," Chemical Physics, vol. 339, no. 1-3, pp. 36-43, 2007.

[32] A. Fujishima, X. Zhang, and D. A. Tryk, "TiO 2 photocatalysis and related surface phenomena," Surface Science Reports, vol. 63, no. 12, pp. 515-582, 2008.

[33] A. Hattori, M. Yamamoto, H. Tada, and S. Ito, "A promoting effect of NH4F addition on the photocatalytic activity of solgel $\mathrm{TiO}_{2}$ films," Chemistry Letters, no. 8, pp. 707-708, 1998.

[34] T. Yamaki, T. Sumita, and S. Yamamoto, "Formation of $\mathrm{TiO}_{2-x} \mathrm{~F}_{x}$ compounds in fluorine-implanted $\mathrm{TiO}_{2}$," Journal of Materials Science Letters, vol. 21, no. 1, pp. 33-35, 2002.

[35] C. D. Valentin, G. Pacchioni, and A. Selloni, "heory of carbon doping of titanium dioxide," Chemistry of Materials, vol. 17, no. 26, pp. 6656-6665, 2005.

[36] C. D. Valentin, G. Pacchioni, A. Selloni, S. Livraghi, and E. Giamello, "Characterization of paramagnetic species in $\mathrm{N}$-doped $\mathrm{TiO}_{2}$ powders by EPR spectroscopy and DFT calculations," The Journal of Physical Chemistry B, vol. 109, no. 23, pp. 11414-11419, 2005.

[37] D. Valentin, E. Finazzi, G. Pacchioni et al., "N-doped $\mathrm{TiO}_{2}$ : theory and experiment," Chemical Physics, vol. 339, no. 1-3, pp. 44-56, 2007.

[38] R. Nakamura, T. Tanaka, and Y. Nakato, "Mechanism for Visible Light Responses in Anodic Photocurrents at N-Doped $\mathrm{TiO}_{2}$ Film Electrodes," The Journal of Physical Chemistry B, vol. 108, pp. 10617-10620, 2004.

[39] J. L. Gole, J. D. Stout, C. Burda, Y. Lou, and X. Chen, "Highly efficient formation of visible light tunable $\mathrm{TiO}_{2}-\mathrm{xNx}$ photocatalysts and their transformation at the nanoscale," Journal of Physical Chemistry B, vol. 108, no. 4, pp. 1230-1240, 2004.

[40] T. Sano, N. Negishi, K. Koike, K. Takeuchi, and S. Matsuzawa, "Preparation of a visible light-responsive photocatalyst from a complex of $\mathrm{Ti}^{4+}$ with a nitrogen-containing ligand," Journal of Materials Chemistry, vol. 14, no. 3, pp. 380-384, 2004.

[41] O. Diwald, T. L. Thompson, T. Zubkov, E. G. Goralski, S. D. Walck, and J. T. Yates, "Photochemical activity of nitrogendoped rutile $\mathrm{TiO}_{2}(110)$ in visible light," Journal of Physical Chemistry B, vol. 108, no. 19, pp. 6004-6008, 2004.

[42] N. C. Saha and H. G. Tompkins, "Titanium nitride oxidation chemistry: an X-ray photoelectron spectroscopy study," Journal of Applied Physics, vol. 72, no. 7, pp. 3072-3079, 1992.

[43] S. Sakthivel and H. Kisch, "Photocatalytic and photoelectrochemical properties of nitrogen-doped titanium dioxide," ChemPhysChem, vol. 4, no. 5, pp. 487-490, 2003.

[44] X. Chen and C. Burda, "Photoelectron spectroscopic investigation of Nitrogen doped Titania Nanoparticles," The Journal of Physical Chemistry B, vol. 108, no. 40, pp. 15446-15449, 2004.

[45] M. Sathish, B. Viswanathan, R. P. Viswanath, and C. S. Gopinath, "Synthesis, characterization, electronic structure, and photocatalytic activity of nitrogen-doped $\mathrm{TiO}_{2}$ nanocatalyst," Chemistry of Materials, vol. 17, no. 25, pp. 6349-6353, 2005.

[46] M. Sathish, B. Viswanathan, and R. P. Viswanath, "Characterization and photocatalytic activity of $\mathrm{N}$-doped $\mathrm{TiO}_{2}$ prepared by thermal decomposition of Ti-melamine complex," Applied Catalysis B, vol. 74, no. 3-4, pp. 307-312, 2007.

[47] T. Ma, M. Akiyama, E. Abe, and I. Imai, "High-efficiency dyesensitized solar cell based on a nitrogen-doped nanostructured titania electrode," Nano Letters, vol. 5, no. 12, pp. 2543-2547, 2005.

[48] B. Naik, K. M. Parida, and C. S. Gopinath, "Facile synthesis of $\mathrm{N}$-and S-incorporated nanocrystalline $\mathrm{TiO}_{2}$ and direct solar-light-driven photocatalytic activity," Journal of Physical Chemistry C, vol. 114, no. 45, pp. 19473-19482, 2010.

[49] H. M. Yates, M. G. Nolan, D. W. Sheel, and M. E. Pemble, "The role of nitrogen doping on the development of visible lightinduced photocatalytic activity in thin $\mathrm{TiO}_{2}$ films grown on glass by chemical vapour deposition," Journal of Photochemistry and Photobiology A, vol. 179, no. 1-2, pp. 213-223, 2006.

[50] C. Shifu, L. Xuqiang, L. Yunzhang, and C. Gengyu, "The preparation of nitrogen-doped $\mathrm{TiO}_{2-x} \mathrm{~N}_{x}$ photocatalyst coated on hollow glass microbeads," Applied Surface Science, vol. 253, no. 6, pp. 3077-3082, 2007.

[51] E. Gyorgy, A. P. D. Pino, P. Serra, and J. L. Morenza, "Depth profiling characterisation of the surface layer obtained by pulsed Nd:YAG laser irradiation of titanium in nitrogen," Surface and Coatings Technology, vol. 173, no. 2-3, pp. 265270, 2007.

[52] M. Kitano, K. Funatsu, M. Matsuoka, M. Ueshima, and M. Anpo, "Preparation of Nitrogen-Substituted $\mathrm{TiO}_{2}$ Thin Film Photo catalysts by the Radio Frequency Magnetron Sputtering Deposition Method and Their Photo catalytic Reactivity under Visible Light Irradiation," The Journal of Physical Chemistry B, vol. 110, no. 50, pp. 25266-25272, 2006.

[53] J. Yang, H. Bai, X. Tan, and J. Lian, "IR and XPS investigation of visible-light photocatalysis-nitrogen-carbon-doped $\mathrm{TiO}_{2}$ film," Applied Surface Science, vol. 253, no. 4, pp. 1988-1994, 2006.

[54] K. Shankar, K. C. Tep, G. K. Mor, and C. A. Grimes, "An electrochemical strategy to incorporate nitrogen in nanostructured $\mathrm{TiO}_{2}$ thin films: modification of bandgap and photoelectrochemical properties," Journal of Physics D, vol. 39, no. 11, pp. 2361-2366, 2006.

[55] Z. Wang, W. Cai, X. Hong, X. Zhao, F. Xu, and C. Cai, "Photocatalytic degradation of phenol in aqueous nitrogendoped $\mathrm{TiO}_{2}$ suspensions with various light sources," Applied Catalysis B, vol. 57, no. 3, pp. 223-231, 2005.

[56] R. P. Vitiello, J. M. Macak, A. Ghicov, H. Tsuchiya, L. F. P. Dick, and P. Schmuki, "N-Doping of anodic $\mathrm{TiO}_{2}$ nanotubes using heat treatment in ammonia," Electrochemistry Communications, vol. 8, no. 4, pp. 544-548, 2006.

[57] Y. Wang, C. Feng, Z. Jin, J. Zhang, Y. Yang, and S. Zhang, "A novel N-doped $\mathrm{TiO}_{2}$ with high visible light photo catalytic activity," Journal of Molecular Catalysis A, vol. 260, no. 1-3, pp. $1-3,2006$.

[58] F. Peng, L. Cai, L. Huang, H. Yu, and H. Wang, "Preparation of nitrogen-doped titanium dioxide with visible-light photocatalytic activity using a facile hydrothermal method," Journal of Physics and Chemistry of Solids, vol. 69, no. 7, pp. 1657-1664, 2008.

[59] C. Sarra-Bournet, B. Haberl, C. Charles, and R. Boswell, "Characterization of nanocrystalline nitrogen-containing titanium oxide obtained by $\mathrm{N}_{2} / \mathrm{O}_{2} / \mathrm{Ar}$ low-field helicon plasma 
sputtering," Journal of Physics D, vol. 44, no. 45, Article ID 455202, 2011.

[60] X. Zhang, K. Udagawa, Z. Liu et al., "Photocatalytic and photoelectrochemical studies on N-doped $\mathrm{TiO}_{2}$ photocatalyst," Journal of Photochemistry and Photobiology A, vol. 202, no. 1, pp. 39-47, 2009.

[61] K. S. Rane, R. Mhalsiker, S. Yin et al., "Visible light-sensitive yellow $\mathrm{TiO}_{2-x} \mathrm{~N}_{x}$ and $\mathrm{Fe}-\mathrm{N}$ co-doped $\mathrm{Ti}_{1-y} \mathrm{Fe}_{y} \mathrm{O}_{2-x} \mathrm{~N}_{x}$ anatase photocatalysts," Journal of Solid State Chemistry, vol. 179, no. 10, pp. 3033-3044, 2006.

[62] Y. Cong, J. Zhang, F. Chen, M. Anpo, and D. He, "Preparation, photocatalytic activity, and mechanism of nano- $\mathrm{TiO}_{2} \mathrm{Co}-$ doped with nitrogen and iron (III)," Journal of Physical Chemistry C, vol. 111, no. 28, pp. 10618-10623, 2007.

[63] J. Wang, D. N. Tafen, J. P. Lewis et al., "Origin of Photocatalytic Activity of Nitrogen-Doped $\mathrm{TiO}_{2}$ Nanobelts," Journal of the American Chemical Society, vol. 131, no. 341, pp. 2290-12297, 2009.

[64] J. Yang, H. Bai, X. Tan, and J. Lian, "IR and XPS investigation of visible-light photocatalysis-Nitrogen-carbon-doped $\mathrm{TiO}_{2}$ film," Applied Surface Science, vol. 253, no. 4, pp. 1988-1994, 2006.

[65] D. Mitorj and N. H. Kisch, "The nature of nitrogen-modified titanium dioxide photocatalysts active in visible light," Angewandte Chemie International Edition, vol. 47, no. 51, pp. 99759978, 2008.

[66] Z. Zhang, X. Wang, J. Long, Q. Gu, Z. Ding, and X. Fu, "Nitrogen-doped titanium dioxide visible light photocatalyst: spectroscopic identification of photoactive centers," Journal of Catalysis, vol. 276, no. 2, pp. 201-214, 2010.

[67] Y.-C. Tang, X.-H. Huang, H.-Q. Yu, and L.-H. Tang, "Nitrogen-doped $\mathrm{TiO}_{2}$ photocatalyst prepared by mechanochemical method: doping mechanisms and visible photoactivity of pollutant degradation," International Journal of Photoenergy, vol. 2012, Article ID 960726, 10 pages, 2012.

[68] M. Pandey and R. S. Pala, "Stabilization and growth of nonnative nano crystals at low and atmospheric pressures," Journal of Chemical Physics, vol. 136, Article ID 044703, 2012.

[69] S. H. Lee, E. Yamasue, H. Okumura, and K. N. Ishihara, "Preparation of $\mathrm{N}$-doped $\mathrm{TiO}_{x}$ films as photocatalyst using reactive sputtering with dry air," Materials Transactions, vol. 50, no. 7, pp. 1805-1811, 2009.

[70] N. Serpone, "Is the band gap of pristine $\mathrm{TiO}_{2}$ narrowed by anion- and cation-doping of titanium dioxide in secondgeneration photocatalysts?" The Journal of Physical Chemistry $B$, vol. 110, no. 48, pp. 24287-24293, 2006.

[71] V. N. Kuznetsov and N. Serpone, "Visible light absorption by various titanium dioxide specimens," The Journal of Physical Chemistry B, vol. 110, no. 50, pp. 25203-25209, 2006.

[72] V. N. Kuznetsov and N. Serpone, "Photoinduced coloration and photobleaching of titanium dioxide in $\mathrm{TiO}_{2} /$ polymer compositions upon UV- and visible-light excitation of color centers' absorption bands: direct experimental evidence negating band-gap narrowing in anion-/cation-doped $\mathrm{TiO}_{2} \mathrm{~s}$," The Journal of Physical Chemistry C, vol. 111, no. 42, pp. 15277-15288, 2007.

[73] R. Beranek and H. Kisch, "Tuning the optical and photoelectrochemical properties of surface-modified $\mathrm{TiO}_{2}$," Photochemical \& Photobiological Sciences, vol. 7, no. 1, pp. 40-48, 2008.

[74] H.-J. Cho, P.-G. Hwang, and D. Jung, "Preparation and photocatalytic activity of nitrogen-doped $\mathrm{TiO}_{2}$ hollow nanospheres," Journal of Physics and Chemistry of Solids, vol. 72, no. 12, pp. 1462-1466, 2011.

[75] C.-M. Huang, L.-C. Chen, K.-W. Cheng, and G.-T. Pan, "Effect of nitrogen-plasma surface treatment to the enhancement of $\mathrm{TiO}_{2}$ photocatalytic activity under visible light irradiation," Journal of Molecular Catalysis A, vol. 261, no. 2, pp. 218-224, 2007.

[76] T. Tachikawa, Y. Takai, S. Tojo et al., "Visible light-induced degradation of ethylene glycol on nitrogen-doped $\mathrm{TiO}_{2}$ Powders," Journal of Physical Chemistry B, vol. 110, no. 26, pp. 13158-13165, 2006.

[77] M. Kitano, K. Funatsu, M. Matsuoka, M. Ueshima, and M. Anpo, "Preparation of nitrogen-substituted $\mathrm{TiO}_{2}$ thin film photocatalysts by the radio frequency magnetron sputtering deposition method and their photocatalytic reactivity under visible light irradiation," Journal of Physical Chemistry B, vol. 110, no. 50, pp. 25266-25272, 2006.

[78] T. Ihara, M. Miyoshi, Y. Iriyama, O. Matsumoto, and S. Sugihara, "Visible-light-active titanium oxide photocatalyst realized by an oxygen-deficient structure and by nitrogen doping," Applied Catalysis B, vol. 42, no. 4, pp. 403-409, 2003.

[79] B. Grzmil, B. Kic, and M. Rabe, "Inhibition of the anataserutile phase transformation with addition of $\mathrm{K}_{2} \mathrm{O}, \mathrm{P}_{2} \mathrm{O}_{5}$, and $\mathrm{Li}_{2} \mathrm{O}$," Chemical Papers, vol. 58, no. 6, pp. 410-414, 2004.

[80] A. Chatterjee, S. B. Wu, P. W. Chou, M. S. Wong, and C. L. Cheng, "Observation of carbon-facilitated phase transformation of titanium dioxide forming mixed-phase titania by confocal Raman microscopy," Journal of Raman Spectroscopy, vol. 42, no. 5, pp. 1075-1080, 2011.

[81] K. Prasad, D. V. Pinjari, A. B. Pandit, and S. T. Mhaske, "Phase transformation of nanostructured titanium dioxide from anatase-to-rutile via combined ultrasound assisted solgel technique," Ultrasonics Sonochemistry, vol. 17, no. 2, pp. 409-415, 2010. 


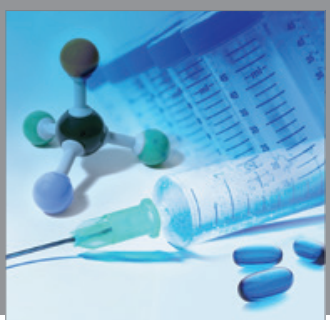

International Journal of

Medicinal Chemistry

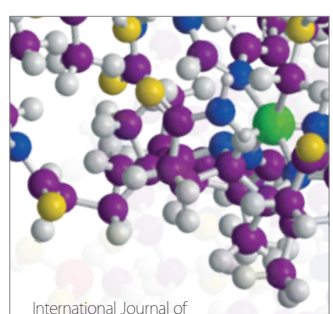

Carbohydrate Chemistry

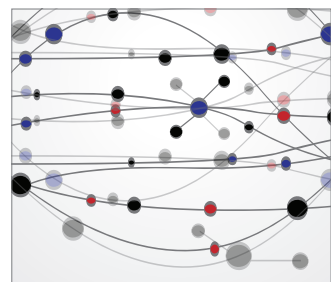

The Scientific World Journal
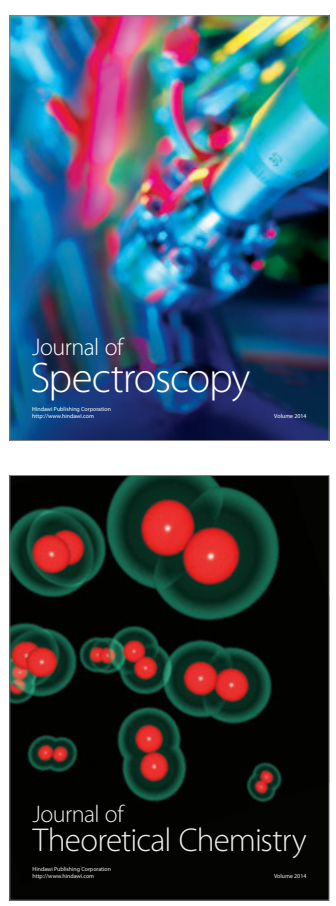
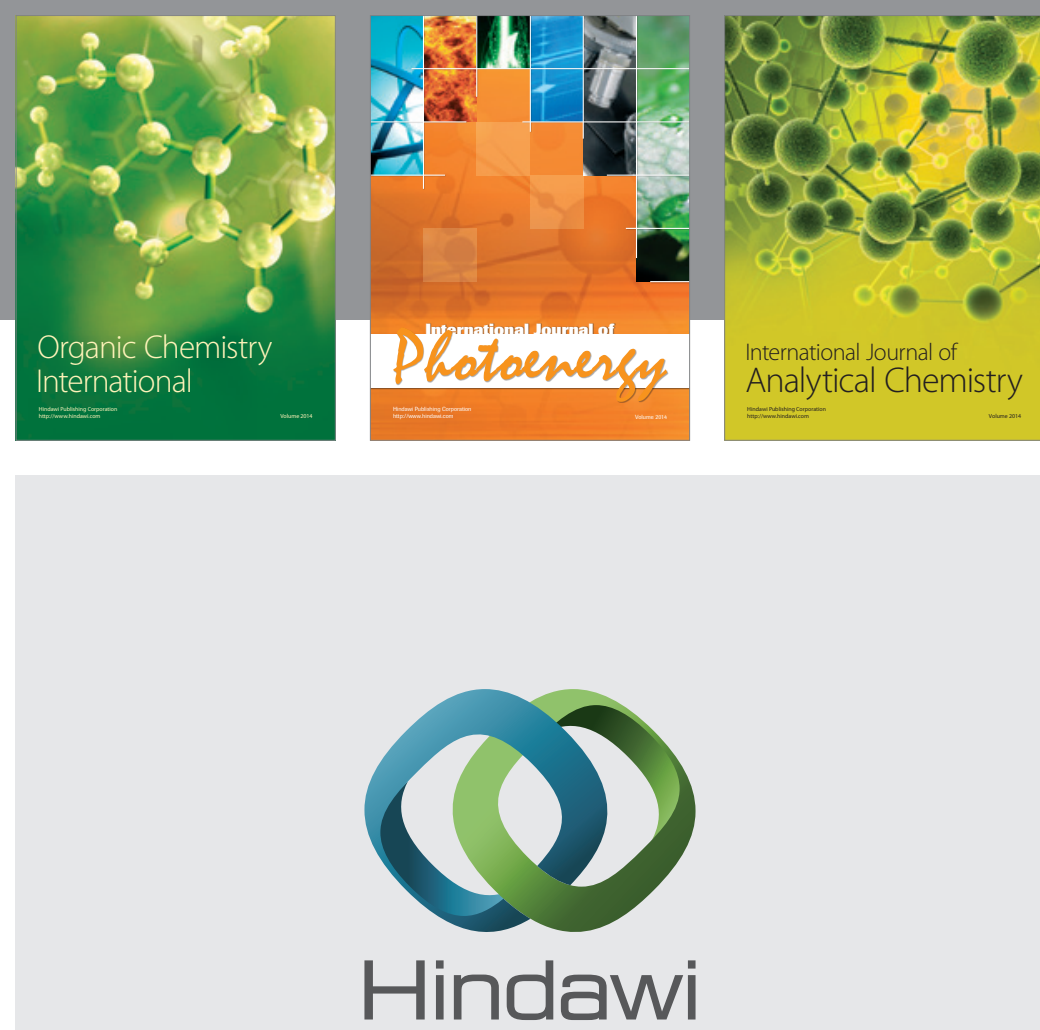

Submit your manuscripts at

http://www.hindawi.com
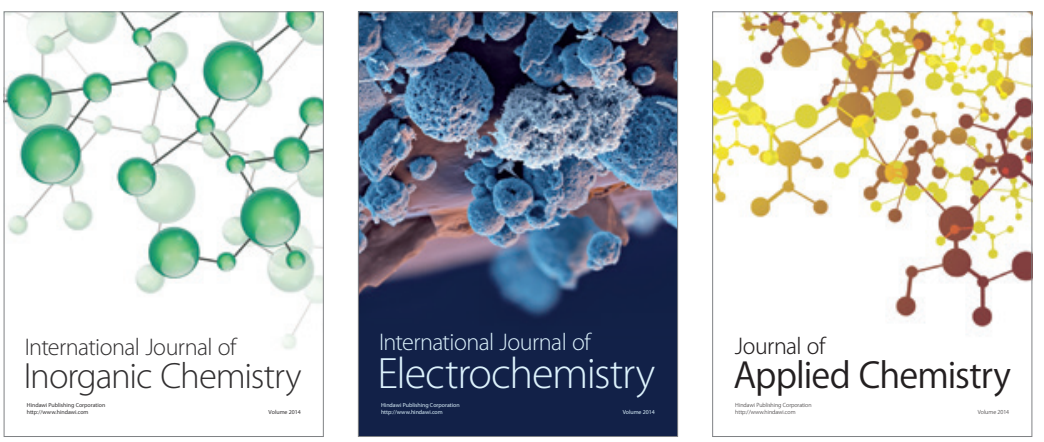

Journal of

Applied Chemistry
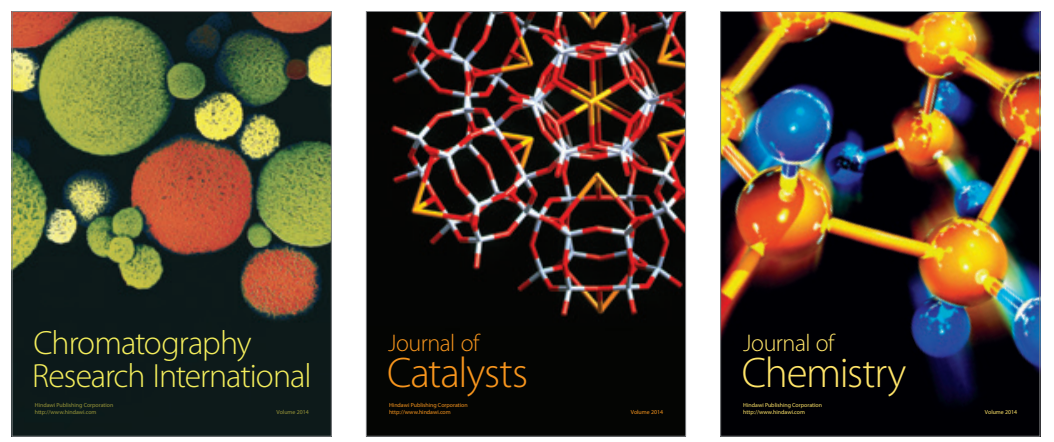
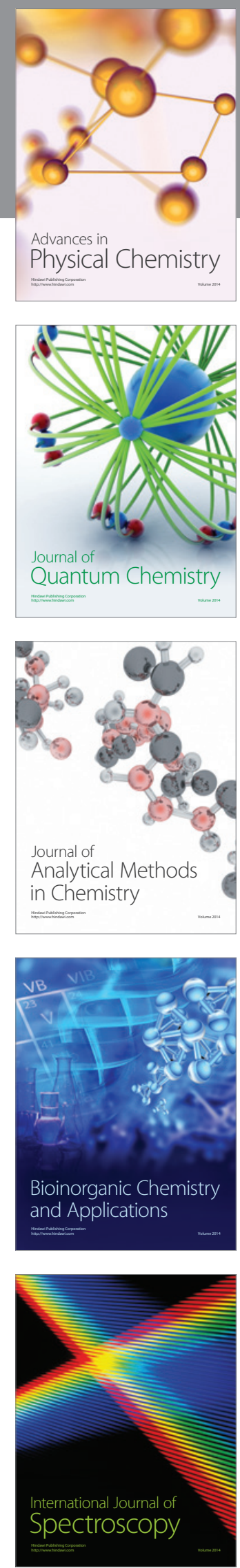